tion and the vast majority of general practitioners.

It is surely time, after the catastrophic medical exodus of 1965 , for the administration to wake up and increase rather than decrease our hopes for the future.

I am not a devotee of any particular mode of remuneration, but it would appear on the face of it that areas of high morbidity would attract much-needed recruitment of medical manpower if doctors were paid for the services they actually performed-that is, itemof-service payment.

This single administrative step would do more than anything else to level up the quality of medical care. The Treasury has obstructed this common-sense and just proposal long enough.

Mr. Minister, please may there be an urgent sense of reality in a rapidly deteriorating situation in general practice.-I am, etc.,

London S.E.3. Howard REEVE.

REFERENCE

1 Taylor, Lord, Good General Practice, 1954. Oxford.

\section{Review Body}

SIR,-The Review Body report is at last imminent, and it is essential that we should not lose sight of the main issue when we consider its details: and it needs to be said again now that the main issue is quite simply a very great deal more money to be spent on general practice. That is to say, quite bluntly, a large increase in the income of the general practitioner, without which recruitment will continue to fall; and unless the numbers of family doctors increases our work load will go on getting heavier. It seems to be becoming fashionable to play down the importance of money in relation to our many present grievances, but in the last resort, whatever else needs doing, more money is an essential prerequisite, which would by itself rid us of the two stumbling-blocks barring the way to any improvement in the standard of general practice in this country -namely, lack of reasonable income and insufficient time to do the job as we know it should be done. These two factors are forcing enormous numbers of young doctors, against their will in many cases, to cut adrift from parents, friends, and their own native land in order to obtain an adequate standard of living and working in other countries. Many of these men and women would prefer to stay here but find that they simply cannot afford to do so, and they must be induced to stay by making the rewards and conditions of practice in this country somewhat more commensurate with those which they know they can find overseas. It is fatuous to say that we cannot afford to do this: we all know that unless such a state of affairs is reached soon the standard of medical care will be as inadequate all over the country as it already is in many areas now.

Furthermore, in view of the increasingly rapid deterioration in the position we must resolutely disown the undertaking made on our behalf by our negotiating team that we, a dwindling number of practitioners, hold ourselves responsible for an ever-increasing population of patients. For one thing, it would be quite dishonest to pretend that we are able to do so ; secondly, it would enable the Government to go on shelving its responsibility for the situation which successive Governments have themselves created by their short-sighted determination to get more and more for the expenditure of less and less; and thirdly, because this undertaking runs directly counter to the statement in the "Charter." We cannot any longer accept a situation where the Government rocks the boat and we are blamed because the passengers get wet and the crew jumps overboard.

Finally, we must be at pains to discount all the crocodile tears and protestations of sympathy from the Minister-he claimed on television recently that he has "coped with a crisis in general practice," but we must in this context remember that his criteria differ from ours, and that his success lies in the fact that the general-practitioner service costs less now than it did when he assumed office, by virtue of the smaller number of doctors in practice, while "production" has gone up not only because of a greater population, but also because by removing the prescription charge he has persuaded patients to consult their doctors more frequently even than before. His recent statement belittling the extra work this has caused, "only one extra prescription per head of population," shows quite clearly that friendly words from the Minister are as good as a kick in the teeth from anybody else. Pertinax (2 April, p. 857) asserts that Mr. Robinson " has in a remarkable way gained the confidence of the medical profession." It would indeed be remarkable if he had.-I am, etc.,

Scarborough.

C. H. Neaves.

SIR,-I believe we are on the eve of accepting a reformed N.H.S. several degrees more bureaucratic and absurd than the one in which we are now struggling.

Having advised by a large majority that the pricing go ahead, there is little we can do but accept the Review Body's award, while quietly hoping that the Government will let us off the hook by referring it to the Prices and Incomes Board.

The realization of truth that swept over the profession at Swansea came too late to be other than an embarrassment to our negotiations and an opportunity 'to the Ministry to expose our weaknesses. Soon after we were voting, virtually without discussion, that the pricing go ahead.

Personally I believe that the Medical Guild project was mistaken from the beginning.

To stand up to the Ministry of Health effectively we need highly cohesive local organizations, nay fellowships, prepared to act on their own if necessary.

To win over the public we need to eschew private schemes, insisting on a reformed N.H.S.

To reform the N.H.S. we need a single objective: the right, if we choose, to charge the patient in certain instances-that is, where the initiative for the visit or consultation rests with the patient. Visits and consultations made on our own initiative as follow-up should be paid for by capitation fee as at present.

To get this we shall have to use considerable moral force. We shall have carefully to shun those politicians who wish us to collect revenues. We shall have to fight only if we have the necessary backing in our local associations based on geographical neighbourhood. We shall have to be absolutely loyal to each other until our objective is obtained. We have, I believe, failed this time, but sooner or later we shall try again.-I $* \mathrm{~m}$, etc.

Bishop Auckland,

M. J. Clay.

Co. Durham.

SIR,-The delay in announcing the Review Body's decision on pricing the contract, caused by the General Election, has been a great boon to general practitioners. It has jolted them back to the reality of the fact that medicine is inextricably bound to politics in the N.H.S., and at the same time has given them a breathing space to view the real issues that will be at stake in the coming weeks.

Some of us had become mesmerized by George Brown's prices and incomes policy and had almost begun to believe that we were personally reponsible for the present economic situation. We were prepared to accept whatever price the Review Body decided to place on our services without a murmur. We had lost sight of the fact that our present clash with the Government (and clash it is in spite of Mr. Robinson's recent reassurance on television that he had "coped" with the problem) is not just another petty pay claim but a last-ditch stand to put right' the injustices of the past 18 years and to decide once and for all whether general practice has any future within the N.H.S. This is what the Charter was about and this is what the new contract should be about.

The British Medical Guild does not hold 18,000 resignations merely to extract an extra 5 or $10 \%$ from the Government. The issues are much greater than this, and we must face them with honesty and courage, because this is our very last chance.- I am, etc.,

\section{Sanderstead,
Surrey. \\ M. M. A. ShIPSEY. \\ Postgraduate Training Posts for Overseas Doctors}

SIR,-May I comment on the views expressed by Dr. W. M C. Allen (26 February, p. 545) and Dr. P. K. Chakrabartty (19 March, p. 740)?

To say the least it is extraordinary that the head of a department of radiology in India should have sought an appointment as registrar in England. Whatever the purpose it could not be postgraduate study. Dr. Allen, however, is not correct in generalizing from this instance, and suggesting that the majority of Indian doctors in Britain are, similarly, not genuine postgraduate students. Perhaps a visit to the examination halls may convince him otherwise.

What is deplorable is the hankering after British qualifications, which has resulted in the influx into Britain of a large number of Indian doctors who, in order to support themselves, take up the unwanted jobs in British hospitals and so provide a variety of blackleg medical labour. I do not think that this is a situation consistent with selfrespect. 